\title{
Travel demand modelling, data collection and well-being
}

\author{
Francesco Manca ${ }^{1} \cdot$ Aruna Sivakumar $^{1} \cdot$ Stephane Hess $^{2}$ \\ Published online: 28 February 2019 \\ ๑) Springer Science+Business Media, LLC, part of Springer Nature 2019
}

The papers included in this special issue have been selected among contributions to the 14th International Conference on Travel Behaviour Research (IATBR), held in Windsor in July 2015. The special issue contains five regular papers and one keynote paper.

The regular papers are in some form all about data collection and survey design. The first three papers are effectively about data collection, the challenges and the opportunities therein; while the first two papers are more focused on survey design, the third paper demonstrates how to exploit repeated cross sectional datasets to improve temporal transferability of demand models. The fourth paper is ostensibly focussed on the impacts of e-shopping on personal shopping mobility, though fundamentally it demonstrates the value of multi-day travel diaries and of combining travel diaries with data on activity participation. The fifth and last research paper in this special issue examines well-being in the context of residential location choice, and the collection of data through appropriate surveys.

The first paper, by Schmidt et al., gives an in-depth explanation of the challenges faced in surveys which include multi-day travel reporting, expenditure and online behaviour, as well as stated preference (SP) components on mode and route choice, and the investigation of daily activity scheduling and mobility tool ownership. Such detailed surveys provide hugely interesting insights, allowing us to explore the effect of large changes in generalized transport costs not only on time allocation, mode choice and activity travel patterns but also on mobility tool ownership in the long term and the suppressed demand from an activity-based perspective. They can however also be beset by issues of drop-out and poor response quality, and findings in this paper show the issues of using high incentives and over-representing subpopulations, as well as the importance of considering fatigue effects.

Auschauer at al. present an innovative survey to simultaneously capture information on three important processes: time assigned to travel activity, time assigned to non-travel activity such as leisure and personal care, and the monetary budget assigned for constrained and unconstrained goods. In this respect, they combine three survey techniques (travel survey, time use survey and consumer expenditure survey) into one. Results illustrate a more reliable dataset that can be used in travel behaviour models.

Salem and Habib present the advantage of using repeated cross-sectional datasets for the temporal transferability of activity scheduling models. In particular, they explore temporal transferability and demonstrate an approach to develop a meta-model which

Aruna Sivakumar

a.sivakumar@imperial.ac.uk

1 Urban Systems Lab, Centre for Transport Studies, Imperial College London, London, UK

2 Choice Modelling Centre, Institute for Transport Studies, University of Leeds, London, UK 
makes it possible to account for temporal evolution in activity scheduling. As illustrated, the use of repeated cross-sectional datasets in this manner improves temporal transferability, and guarantees a more reliable tool for travel demand forecasting.

The fourth paper in this special issue investigates the effect of e-shopping on the different stages of personal shopping mobility, from browsing to purchasing of products. Factor analysis techniques are employed to categorise different groups with specific browsing and selection behaviour. Multivariate linear regression models are employed to analyse a 3-day travel diary dataset of shopping trips in order to understand whether e-shopping influences trip distances. Findings show that e-shopping does significantly influence non-grocery shopping trips while this influence is not significant for grocery shopping trips.

By combining ideas from psychology and transport studies, Bhattacharyya et al. discuss the design and implementation of two types of interventions (focalism and visualisation) to encourage a more rational residential choice and consequently lead to more sustainable travel behaviour. The survey was conducted before and after the residential choice, and the authors find that, depending on the interventions, people make more sustainable decisions and their happiness increases.

The special issue concludes with a keynote paper in which Mokhtarian gives an overview of methodologies to assess how travel affects well-being. The concept of subjective well-being is clarified and different types of conceptual models that analyse the influence of transportation on subjective well-being are reviewed.

We believe these six papers give an idea of the diverse set of topics discussed at IATBR 2015 .

Publisher's Note Springer Nature remains neutral with regard to jurisdictional claims in published maps and institutional affiliations.

Francesco Manca is a postgraduate researcher at the Urban Systems Laboratory, Centre for Transport Studies, at Imperial College London. His research interest lies in travel behaviour analyses, development of advanced transport models and transport planning. His expertise enables him to investigate the demand of transport systems and the potential adoption of new transport technologies. His recent research was focused on the inclusion of social influence processes in travel and travel behaviour and on the analysis and forecast of new transport modes in major urban projects. His works have been presented in peer-reviewed international conferences and journals.

Aruna Sivakumar is a senior lecturer in consumer behaviour and urban systems at the Centre for Transport Studies, Imperial College London. She is executive director of the Urban SystemsLaboratory, and leads several smart city and systems modelling initiatives. As PI, she has attracted funding worth $£ 1.2 \mathrm{~m}$ over the last 5 years from national and international sources such as EPSRC, ESRC, Shell Inc in the UK, and SMRT Singapore. Over a career spanning 15+ years Aruna has published more than 40 peer reviewed journal papers, made over a 100 conference presentations, and published several book chapters. She has a h-index of 16 (google scholar)/11 (Scopus), i10 index of 21, and her review paper on urban energy systems has been cited over 150 times over the 6 years since it was published. Her research on activity based microsimulation models of urban resource demands is internationally renowned and she has been invited to present at several seminar series, such as the UCL Energy series. Aruna is a recipient of the prestigious Milton-Pikarsky award for her MSc research in the US, and was awarded a University Transportation Center prize as a PhD at the University of Texas at Austin. She is a member of several scientific committees, including the Travel Behaviour and Values subcommittee of the Transportation Research Board (TRB) in the US, and the 'Infrastructure Operation and Traffic Management in Developing Countries' committee of the World Conference on Transport Research Society (WCTRS). She is an editorial board member of Transportation Letters, and a founding stakeholder of the Zephry Foundation for Advancing Travel Analysis Methods. 
Stephane Hess is Professor of Choice Modelling in the Institute for Transport Studies and Director of the Choice Modelling Centre at the University of Leeds. He is also Honorary Professor in Choice Modelling in the Institute for Transport and Logistics Studies at the University of Sydney, Honorary Professor of modelling behaviour in Africa at the University of Cape Town, and has a director position at RSG, a leading North American consultancy company. Hess holds a PhD in transport demand modelling from Imperial College London and a MPhil in Statistical Science from Cambridge University. His area of work is the analysis of human decision using advanced discrete choice models, and he is active in the fields of transport, health and environmental economics. Hess has made contributions to the state of the art in the specification, estimation and interpretation of such models, notably in a valuation of travel time context, where he has led the modelling on the most recent UK, German and Singaporean national studies, as well as the reestimation of the Swiss study. He has published over 100 peer reviewed journal papers and has been involved as a principal or co-investigator in academic projects with a combined income generation of over $£ 9.5 \mathrm{M}$. His contributions have been recognised for example by the 2014 Outstanding Young Member of the Transportation Research Board (TRB) award for exceptional achievements in transportation research, policy, the 2010 Fred Burggraf award handed out by the Transportation Research Board, the 2005 Eric Pas award for the best PhD thesis in the area of travel behaviour modelling, and the 2004 Neil Mansfield award handed out by the Association for European Transport. He is also the founding editor in chief of the Journal of Choice Modelling and the founder and steering committee chair of the International Choice Modelling Conference. $\mathrm{He}$ is an associate editor of Transportation Research Part E, and serves on the editorial advisory board of two other leading journals; Transportation Research Part B and Transportation, as well as academic committees at leading international conferences. 